\title{
Introduction: Europe, Heritage and Memory-Dissonant Encounters and Explorations
}

\author{
Iris van Huis, Sigrid Kaasik-Krogerus, \\ Tuuli Lähdesmäki and Liliana Ellena
}

Heritage and memory, as closely related concepts, have great relevance to our world and European society today. Contemporary Europe faces political, economic, social, and humanitarian challenges that influence both how people deal with their past and how they build their identities

\section{I. van Huis}

Faculty of Social and Behavioural Sciences, University of Amsterdam, Amsterdam, The Netherlands

e-mail: iris@vanhuis.com; i.vanhuis@uva.nl

S. Kaasik-Krogerus · T. Lähdesmäki $(\square)$

Department of Music, Art and Culture Studies, University of Jyväskylä, Jyväskylä, Finland e-mail: tuuli.lahdesmaki@jyu.fi

L. Ellena

BABE Research Associate, European University Institute, Florence, Italy e-mail: liliana.ellena@eui.eu

(C) The Author(s) 2019

T. Lähdesmäki et al. (eds.), Dissonant Heritages and Memories in Contemporary Europe, Palgrave Studies in Cultural Heritage and Conflict, https://doi.org/10.1007/978-3-030-11464-0_1 
and ideas of the future as they remember and reshape the past within, and related to, larger power structures.

With, on the one side, the ongoing debates on migration proving a divisive issue with regards to understandings of European integration and identity, and, on the other side, the EU investing more and more in projects related to European heritage, museums, and cultural-memory networks, the dynamics between transnational and transcultural memory-making in Europe make for a significant and compelling case study. To pull together the concepts of "Europe" and "transnational memory" reveals a complex puzzle that poses challenging questions for anyone involved in academic research, heritage practices, and policy debates. Contemporary Europe includes both old and new nation states' borders and those of the European Union, a sui generis supranational political formation. These intersect with the endless ways in which individuals and groups forge their relations to the world in manners that diverge from the geopolitical borders imposed upon it.

With this puzzle at its core, this volume explicitly focuses on slippery and transforming notions of Europe and critically discusses the above-mentioned challenges' impact on power structures of heritage and memory in today's Europe. These challenges and the multifaceted transformations of European societies they brought about impact the practices, processes, and discourses of heritage and memory, including collective and individual struggles over them. To consider the relationship between mobility and European memory requires acknowledging the role of multiple and conflicting combinations of time and space in "shifting patterns of spatio-temporal overlap and disjunction" (Donnan et al. 2017, 2). Accordingly, we approach contemporary European heritage and memory regimes through a critical analysis of both institutions and the embodied experiences of individuals, including those born in Europe and those who have migrated to Europe from across its current borders. The volume explores the intersections of heritages, memories, and identities by approaching them as constituted by the politics and actions of both institutions and individuals.

The volume thus seeks to scrutinize contemporary European heritage and memory regimes from "above" and "below" simultaneously, agreeing with Chiara De Cesari and Ann Rigney $(2014,4)$ that 
studying transnational memory opens up "an analytic space to consider the interplay between social formations and cultural practices", as well as "between state-operated institutions of memory and the flow of mediated narratives within and across state borders". Cross-border dynamics, human movements, and cultural circulation all shape the ways in which individuals and groups accommodate and reinvent the relationship between past and present within historically and socially specific languages, ideologies, and power relations. At the same time, supranational and intergovernmental institutions and actors play an increasingly important role in addressing audiences and policies, allocating funding, and transforming the cultural values attached to specific heritages.

In this light, this volume combines theoretical and methodological contributions to the debates on European heritage and memory studies and in-depth analyses of empirical case studies. Its main aim is to bring these two research fields into a closer dialogue and thus explore the cultural and political dynamics of contemporary Europe.

\section{Encounters at the Crossroads of Research Agendas}

The book is the result of an encounter and dialogue between two different research projects that were both stirred by an interest in the transnational and transcultural dimensions of memory across contemporary Europe, EUROHERIT and BABE. The first focuses on the European Union's (EU) heritage policies and politics in order to explore and critically assess the assumptions on which the idea of a European Heritage is framed and implemented in different EU heritage initiatives. The research builds on the potential and limitations of various connections between cultural heritage, European identity, and memory. The empirical material on which EUROHERIT's research in this volume is built consists of policy documents, cultural sites' promotional and information material, and exhibitions that explicitly address the European dimension of heritage. The BABE research project, meanwhile, centers on the mobility of human bodies that cross frontiers, both geographical and cultural, in and around Europe within the global diaspora. It aims to explore the changes this global mobility has on visual memories of Europe, focusing on memory's artefacts and narrations produced by mobile people and on contemporary art. 
BABE approaches cultural memory as reflected in various cultural products and material cultures produced by movements across borders, foregrounding subjectivity and transcultural practices as rooted in everyday life.

The tensions generated by the two projects' different premises have accompanied the design and writing of the book. The first set of tensions revolve around the ways in which the two projects thematize "Europe". In this volume, EUROHERIT's researchers approach Europe from the point of view of institutional actors and discourses shaped by institutional practices, specifically the guidance, control, and regulation of heritage policies and management, whether on the supranational, national, or local levels. BABE, on the other hand, explores Europe from the perspective of subjective narrations. The ways in which Europe is thus imagined, experienced, and resisted are considered part and articulations of the lived experience of movement itself.

The second set of tensions concerns the discrepancy between conceptualization of memory as produced and negotiated by institutional and political discourses, and one of memory as an intersubjective and embodied practice. The first emphasizes the power structures included in heritage policy discourses and heritage management practices and how they seek to create subject positions, top-down identities, and a feeling of belonging among citizenry in Europe (Lähdesmäki 2014, 2017). The second emphasizes how the narrations people use to sustain their own identity and their identifications with others and the world at large are shaped by intercultural contact and exchange. If memory is a constitutive dimension of the subjects' ongoing self-creation and adaptation within the world around them (Passerini 2007, 2016), the cultural processes of negotiation, appropriation, and reinvention increasingly occur within transnational and transcultural contexts.

Despite these differences, the dialogue developed in this book is built on three key interfaces between the two projects. Firstly, both projects involve the changes and challenges that have marked post-Cold War Europe in political and cultural terms. The fall of the Berlin Wall and the disintegration of the Soviet bloc have inspired plans and hopes for a new European order that is able to fulfil the ideal of a Europe of peace founded on human rights and democracy which was put forward in the immediate post-World War II period. The reunification of Europe and the enlargement of the EU are the two most evident processes that have influenced the development of new cultural practices and policies at 
the EU level. These have emerged along with, and also in response to, recurrent upheaval in Eastern Europe, the enduring economic unbalance between East and West, and the global war on terror after $9 / 11$. The 2008 financial crisis and the politics of austerity, meanwhile, have reproduced a North/South dichotomy and have intersected with responses to the increasing migration stemming from wars, growing economic exploitation, political instability, and the effects of the structural adjustment programmes imposed by the International Monetary Fund and the World Bank on the so-called Third World.

The 1990s saw the third wave of the European integration, as the process of cultural Europeanization intensified in relation to the collapse of the communist regimes and the end of the Cold War. In this context, memory and commemorative practices have become a cornerstone for cultural integration, the attempt to enhance the spread of common values among the citizens of the EU's new and old member states (Karlsson 2010). While freedom of movement has been celebrated as one of the key achievements of the EU's 2004 and 2007 enlargements, the Schengen Agreement on free movement in the signatory countries and the Dublin Convention addressing the responsibilities for examining asylum seekers' applications reveal a strict relationship between European integration and the development of a restrictive migration policy. And not only that, but the securitization of Europe's external borders associated with Fortress Europe has been legitimized and implemented through racialized notions of Europe rooted in hierarchal ideas of identity and civilization forged during colonial modernity (Goldberg 2006; Van Houtum 2013; De Genova 2016).

This volume's main timeframe is between now and 2004 (the largest expansion of the EU), as this is an ideal period to explore the potentialities and paradoxes underlying the relationship between memory's changing configurations under the contemporary global intensification of human mobility on the hand and the use of cultural heritage to enhance forms of identification with Europe on the other. In this regard, the politics of memory play a crucial role within the volume, which explores how acts of remembrance and representations of the past relate to power, identity formations, and political actions and struggles from different perspectives. Its various contributions all articulate the double role played by memory: though memory is key to claims of recognition and empowerment on the part of subjects and groups in marginalized positions within Europe, it is also part of power/knowledge regimes that 
define forms of selective inclusion and exclusion. The politics of memory that emerge from discussions on heritage policies call attention to the fact that memory practices "from below" need to be accompanied by concomitant radical changes "from above" in the political conditions of migrants' and refugees' lives for these practices to achieve their full potential. This reveals the tension between transcultural ethics and praxis of memory on the one side, and its material and political preconditions on the other (Rotheberg and Moses 2014).

A second, related interface between this volume's two research projects is represented by the relationship between borders and belonging, which constitutes a central focus when investigating both memory practices and heritage uses. The link between durable, tangible heritage and the idea of continuity of people across generations is widespread, implicit—and often also explicit-in the Western world, especially Europe. Sharon Macdonald's study on remembrance practices in Europe (2013) emphasizes how ambitions of materializing remembrance always involve materializing identity. This relation between political space and culture based has also been sustained by assuming that territory, social formation, mentalities, and memories are isomorphic, as argued by Astrid Erll $(2011,7)$. As much as the idea of "container cultures" has been contested, not only as ideologically but also epistemologically untenable, over the last decades a rich literature has investigated how borders constantly recompose themselves both outside and inside the European space in connection with the crisis of the nation state, the European constitutional process, the interplay between local and global dynamics, and the ongoing transformations enacted by migrants and their movements from and to Europe (Mezzadra and Neilson 2013; De Genova 2017).

Drawing on these debates, this volume considers memory and heritage as battlefields of border-making and border-crossing, constituted first and foremost by regimes of practices. From this point of view, migration and heritage policies interact and mutually shape the practice of bordering. As suggested by multiple authors working at the intersection between critical border studies and memory studies, the verb "border" is a better fit than the noun to address the processes, activities, and procedures through which the individual and collective past is called into question and reframed in order to make sense of individual trajectories and imagine and organize cultural and political life (Oates-Indruchová and Mueller 2017; Donnan et al. 2017, 2). In this volume, bordering involves the interplay between social ordering and memory-making, 
and is understood as a practice that disseminates borders in physical and socio-political space that is strictly related to politics of belonging (YuvalDavis 2011). Several contributions deal with border zones between nation states and continents, or borders within city spaces, where technologies of everyday belonging intersect with larger legal and policy contexts. The different geographical frameworks in each chapter show how the values and meanings that are attached to Europe in connection to memory and heritage are not just defined at the EU level, but emerge within and across a multiplicity of contexts, which include world-heritage policies and protocols, national and regional settings, and even single sites. In addition, focusing on the tensions between various "scales" of memory-subjective, local, regional, trans-European, diasporic-we aim to contribute to the debate in the field of memory studies on the "scalarity" of memory by inscribing it within the specificities of the EU frame (De Cesari and Rigney 2014; Kennedy and Nugent 2016).

The third and last main interface between the two research projects is presented by the relationship between memory and heritage. For a long time, the heritage-memory dyad has been sustained by a series of dichotomies like individual/collective, material/immaterial, and subjective/ official. Yet these oppositions have been transformed by the shifting meanings of "memory" and "heritage" across the humanities and social sciences.

Scholars in memory studies have long approached memory as a process in which individual and collective dimensions mingle. Simultaneously, memory itself has become an elastic concept which is frequently applied in studies dealing with interpretations of the past, human experiences and self-understanding, and meaning-making of various cultural and social phenomena. It has been localized within a broader framework of social and cultural practices and artefacts (Brockmeier 2010; Pakier and Stråth 2010), and perceived as produced within sociocultural settings defined by specific resources and asymmetric access to them. For Jens Brockmeier (2010), memories are "trans-individual" cultural creations which are made sense of through stories and are often materialized and objectified, for example in monuments, museums, libraries, anniversaries, and landscapes. The materiality of memories is embedded in explanatory and interpretive discourses, in which narratives play a crucial role (Brockmeier 2010). Memory thus is an act intermingled with language in its manifold oral, written, and performative forms. This cultural aspect of memory emphasizes the intertwined nature of past and present, 
"truth" and stories (Lähdesmäki 2017). And, as several chapters in this volume indicate, understanding it like this makes it possible to understand how memories are created, transformed, and cemented through the narration and materialization of stories.

Sociocultural setting and narration are also crucial parts of heritage. Scholars in heritage studies have emphasized how heritage is not a material thing, but rather an act of communication (Dicks 2000), a cultural process, and a performance dealing with the assertion and mediation of historical narratives and collective memories, and the cultural social values that underpin these (Waterton and Smith 2009, 15). Heritage only emerges when something is narrated, defined, and/or treated as heritage in the "right" sociocultural context.

Uncovering the key role that "dissonance" plays in discussions of different uses of memory and heritage in Europe is one of the most productive outcomes of the dialogue that shaped this book. We acknowledge how dissonance opened up new perspectives in the field of heritage studies, where it was originally introduced to discuss heritages that involve discordant stories and public uses of memories and representations of pasts that are contentious (Tunbridge and Ashworth 1996). Further conceptualizations of the dissonance of heritage have foregrounded how dissonance should not only be understood as a culmination of divergent views or as an open conflict over the meanings of heritage, but conceived in relation to the ever-changing values attached to heritage both in time and within and across communities. Instead of emphasizing dissonant heritage as a heritage type distinct from "normal" heritage, Višnja Kisić $(2017,31)$ has conceptualized "heritage dissonance" as an intrinsic quality of all heritage that does not pose a problem in itself but includes "a tension and quality which testifies to the play among different discourses, and opens the space for a number of diverse actions".

Rather than dissolving the tension between memory and cultural heritage, the perspective put forward by the volume builds on their multiple interrelations in order to shed light on implicit or overlooked dimensions. The volume's contributions articulate different engagements with the concept of migrating heritage (Innocenti 2014), both in implicit ways, embedded in migrants' oral self-narrations, and in more explicit forms dealing with struggles over the decolonization of Eurocentric museum and heritage practices. In a parallel move, studying the transcultural dimensions of memory-making discloses the relevance of critically considering European heritage policies from the points of view of 
individual and groups not fully recognized as European. The interaction between the two research projects on these issues thus is particularly evident in the book's discussions of exhibitions, museums, and artistic practices.

In this volume, belonging, memory, and heritage are approached and discussed as entangled concepts that get their power from their narrative and performative nature, that is, their ability to produce reality, action, and affect. Since the linguistic, narrative, and cultural turns in the social and human sciences, identities have been explained and theorized as processes constantly produced, varied, and altered through representations and narration. People tell stories about themselves in order to give continuity to their existence, but narratives also produce and express the shared and public aspects of identities (Delanty and Rumford 2005, 51). Narratives thus are a means to connect the "self" and the world, as well as past and present. However, stories are always created within a certain cultural context and narrative order that "delimit what can be said, what stories can be told, what will count as meaningful, and what will seem to be nonsensical", as Steph Lawler (2002, 242-243) points out. For her, narratives are powerful in the way they structure and renew certain cultural meanings and, conversely, foreclose others (Lawler 2002, 252). In this volume, identities are examined by emphasizing their cultural and narrative qualities, and their processual and ongoing nature. Moreover, narration is considered as a form of social action in which various "mute" cultural phenomena, such as those defined as heritage, are operationalized by language and turned into symbolic markers of identities.

\section{Dissonant Heritages in Europe}

This volume's contributors draw on "dissonant heritage" to analyze, interpret, and rethink contemporary challenges, all the while adding new angles to the concept in the process. Though their combined perspectives are not free from dissonances themselves, together these different viewpoints provide dialogues and insights that can be helpful for future scholarly debate and research in various fields.

As explained above, the concept of "heritage dissonance" helps examine how the past is used in present situations, thereby indicating a lack of agreement and consistency in the meaning and content of heritage (Tunbridge and Ashworth 1996, 20; Kisić 2017). In this volume, that 
insight has been key to shed light on heritage sites, objects, and practices that have recently gone through changes or received formal recognition, more specifically, sites that have acquired the European Heritage Label: a label awarded by the EU to monuments, cultural landscapes, places of remembrance, or cultural goods that are seen as landmarks in the creation of Europe and/or the EU. The processes towards this recognition and the changing narratives involved not only evince struggles over heritage in micro and institutional settings, but they also illuminate broader contemporary heritage challenges: attempted constructions of European and national identities, for instance, and how these can create dissonances, or how the colonial past is remembered or fails to be a part of these constructions. The contributors to this book examine how current debates are materialized, showing how physical and symbolic places help understand broader heritage dissonances. This includes reflections on the "domestication" of what the EU proposed as European heritage and on the Europeanization of national heritage that reveal the flows between, and struggles over belonging by, nation states, the EU, and Europe (Kaasik-Krogerus in this volume).

This volume extends such reflections to places that are not commonly seen as heritage sites, such as ethnography museums, airports, refugee camps, and other borders or sites of transit, including the Mediterranean basin. Dissonant heritage is a useful concept for examining such places, and the objects and bodies in them, because it reveals how they are part of more than just institutional heritage struggles, also showing how subjects shape and understand heritage struggles through their bodily experiences at these sites, which of course depend on a subject's positioning. Examining these "sites of dissonance" (Trakilović in this volume) and how different subjects experience them reveals how certain subjects' bodily experiences and practices influence how particular places and their past can form a dissonant heritage for marginalized subjects. By analyzing the dissonant heritage of such places, this book extends the scope of the concept, exploring new ways of applying and conceptualizing it while building on the work of others (e.g. Tunbridge and Ashworth 1996; Kisić 2017).

This extension of the concept's scope also accounts for this volume's contributions' use of dissonant heritage in relation to intangible heritage. Although it is not the first to do so (Deacon 2004; Smith 2006; Smith and Akagawa 2009), this volume includes an elaborate discussion of how intangible heritage is especially used in nationalist identity 
politics (van der Laarse in this volume). This usage risks fixating cultural activities that are assumed to be "authentic" characteristics of national identity into static (and thus "inauthentic") forms and are therefore in need of critical evaluation. This is also relevant in any analysis of (the creation of) "authorized heritage discourses" (Smith 2006, 29-34). This concept refers to the way agents in power control and regulate practices and discourses, which commonly leads to the formal fixation of heritage through policy, administrative, and legislative documents. UNESCO and the EU are examples of such agents listing heritage sites that they consider as important to be transmitted for future generations. Several contributors to this volume particularly investigate how the EU's practice of awarding sites with the European Heritage Label produces their European content, for example by emphasizing certain "European values" (Mäkinen in this volume; Turunen in this volume). This EU label seeks to spread a unifying EU discourse, bypassing dissonances included in the concepts of Europe, heritage, and values in Europe.

Appearing in contributions from both research projects, perspectives from postcolonial and decolonial theory help critically examine dissonant heritages in the European context. As has been rightly argued by postcolonial theorists, this theory is useful beyond research on former colonies and postcolonial migrants in Europe, as it offers perspectives on Europe that challenge the "insularity of historical narratives", which is desperately needed (Bhambra 2014, 117; also discussed by Turunen in this volume). In relation to heritage, such perspectives help challenge European heritage narratives that are presented as universal and objective, thereby "marginalizing and silencing other experiences and voices" (Bhambra 2014, 117). Besides engaging with these problematic static and objectivist discourses critically, contributors in this book have looked beyond the physical space of Europe and the EU, examining diasporic relations and (dissonant) memories beyond Europe. The way memories and heritage are "used, misused and exploited" (Said 2000, 177-179) in the creation of national and cross-national identities, as well as in the way divergences between "we" and "they" are constructed (and possibly broken down), is discussed from several theoretical perspectives as well as through the lens of interviewees who migrated to Europe. These interviewees reflect both on their individual identity and on colonial history, discussing their thoughts and emotions when moving between memories of their journey and of colonial heritage, and thus offering dissonant "emotional geographies" (Davidson et al. 2012; Proglio in 
this volume). Activists who protest the way the European colonial past is (not) represented in heritage sites, including the way dichotomies between Western art and non-Western artefacts are reproduced in ethnographic museums (van Huis in this volume), have further incited critical reflections, resulting in a conversation between academic production and artistic and activist practices.

Our chosen theoretical and methodological approaches have led to insights that help examine in greater detail how dissonance is publicly expressed in heritage and memory. Such approaches helped analyze how heritage dissonance can be less or more strongly felt, as well as more or less publicly voiced, depending on moments in time and different actions. During times of protest, heritage dissonances, as embodied experiences that might be omnipresent in individual subjects' lives, are transformed into representations visible in public (van Huis in this volume). These expressions of dissonance can be used as powerful political instruments that make those being protested uncomfortable (though they can affect protesters themselves as well), making it possible to further scrutinize and speak back to majority populations and institutions. These moments of dissonance can furthermore be understood as forms of disrupting "white innocence" (Wekker 2016), an internalized self-image of the majority population-constructed over centuries of colonialism as part of a collective cultural archive (but paradoxically ignoring large parts of this history) - that ignores racism and white privilege exists (as well as sexism, ableism, homophobia, classism, etc.). Such bottom-up moments of disruption, of overt heritage dissonance, show that there can be more equitable processes than the top-down integration interventions common to the cultural policies of nation states and the EU.

Together, these perspectives - the critical analysis of institutionalized formal discourses and struggles over formalization, the extended scope to include intangible heritage and sites that are not commonly associated with heritage, and the bottom-up approach to analyze individually experienced dissonance as used in political and artistic practice-form crucial contributions to dissonant-heritage theory and can be further used in scholarly debate and research, not only in the fields of history, and heritage and memory studies, but also political science, anthropology, sociology, cultural studies, geography, and beyond. At the same time, we are aware that traces of Eurocentrism remain in this book. Although we aimed to critically study European heritage, memory, and identity, the focus on Europe in itself sometimes directed the book 
towards reproducing a cohesive idea of European identity and heritage, and more divergences can be seen when these issues are examined more closely or broadly. Between the chapters and between the two research groups there were also divergences in the way dissonant heritage and memory are examined. The most important differences are found in the way contributors view heritage, either from the institutionalized perspective or from the bottom up, and in the extent to which the idea of a unified European identity and the idea of a shared European heritage is criticized. Furthermore, extending the concept of heritage to places and practices that are not commonly viewed as such is mostly done by the BABE's research group, whereas the institutionalization is mostly studied by the EUROHERIT team, although there are also overlaps. These overlaps are also thematic, and therefore all three sections of this volume have contributors from both research groups, offering institutional and bottom-up perspectives to each theme. The failure to thoroughly discuss gender and class is another issue that leaves us feeling uneasy. Gender is discussed in the intersectional perspective used by an activist group protesting representations of the colonial past in an ethnographic museum (van Huis in this volume), but gender and class deserve more attention when discussing heritage, memory, and identity because they are crucial dimensions to how these are formed and how they impact our lives.

Altogether, dissonance-this uncomfortable sense of disharmony, confusion, or conflict-has been a central sensitizing concept in the writing and composition of this volume's chapters. It revealed itself able to lead us to new ideas and sometimes to new harmonies. It helped bring researchers from different backgrounds and research interests together, while also constructively acknowledging the continuing dissonance between and within our work, and the need to be even more critical in the future. In the course of the book's development, dissonance has not only been explored with reference to our fields of research, but it also increasingly became a part of our encounter's development into a fruitful and creative conversation. Dissonance was extended to include discrepancies not just between different directions of research or theoretical frameworks, but also to different uses and understandings of the very concepts that had originally fostered our encounter: "Europe" and "transnational memory". By moving back and forth between the points of convergence and divergence between different scales of analyses, conceptual tools, and objects of research, dissonance has increasingly become more of a method of thinking and of asking each other 
questions. After all, the metaphor of dissonance, borrowed from music theory, reminds us that what is considered stable or unstable, pleasant or unpleasant, in the interaction between different sounds does change over time. Sounds thus not only produce friction, but also interpenetration and exchange. What Joan Scott $(2011,78-79)$ has noted for reverberations can be applied also to dissonances: they characterize the non-linear ways in which circuits of influences work in our globalized present.

These elements also inform the experimental mode of the book in which the mobility of borders applies just as much to research practices and disciplinary languages. This volume thus does not aim to recompose different perspectives into a coherent frame, but to highlight the productive and creative effect of frictions and connections emerging from the different contributions.

\section{Explorations of Heritage and Memory Dissonances in Contemporary Europe}

This volume examines the web of dissonances emerging from the triangulation of heritage, memory, and contemporary Europe. At the core of its structure are two phenomena: on one side the contradictions raised by attempts to establish a direct link between cultural and political identity, and on the other the challenges that contemporary responses to the transformations of European societies by global forms of governance, transnational interactions, and movements of people within and across borders pose to understandings of memory and heritage. The main tension between heritage policies and memory practices is not only refracted and complicated by the specificity of this volume's case studies, but also by the variety of methods authors deploy in their analyses. They include participant observation, close reading of images, discourse analysis of speeches and official documents, interviews, auto-ethnography, and social network analysis. The chapters of the volume are divided into three sections that identify the main convergences of our conversations and exchanges.

The first section opens the volume with a discussion of the role that uses of Europe's conflicted and martial past play in contemporary heritage discourses. These chapters discuss both conflicts and the attempts to solve and reconcile them in recent heritagization processes and transnational heritage policies of the Council of Europe, the EU, and UNESCO. The section thus explores European heritage and memory regimes "from 
above", focusing on "authorized heritage discourses" that construct and maintain these regimes through linguistic and discursive practices and performative processes. The section starts with Tuuli Lähdesmäki's analysis of the heritage policy discourses of two core European-level political actors, the EU and the Council of Europe, exploring how these actors deal with the challenges the idea of heritage faces in postmillennial Europe, and the opportunities to respond to these challenges. The analysis reveals how, on the one hand, the EU and the Council of Europe recognize and seek to reconcile heritage-related conflicts in contemporary Europe. These attempts see heritage as a space for civil participation, interaction, intercultural dialogue, and conversation about divergent values and narrations of the past. On the other hand, the policy discourses and their conceptions often rely on a static and materialist notion of heritage, which sustains geographical, cultural, political, socio-economic, and religious power hierarchies, not to mention an exclusive notion of a common European cultural heritage.

Katja Mäkinen continues the discussion of the EU's problematic relation to Europe's past in her analysis of the inter-conceptualization of Europe and the idea of peace. She particularly examines the meanings that the remembrance of World War II take on in the European integration process and in the imagination of the EU as a peace project. Her empirical analysis focuses on the European Heritage Label, the European Commission's recent flagship initiative, more particularly nine sites that have received this label on the basis of their aims to build peace in Europe. The chapter discusses how these sites' informational and promotional material presents the physical, practical, and imagined aspects of peace, how cultural heritage is entangled with political heritage, and how heritage's tangible and intangible dimensions of are intertwined in the EU's attempts to tell a European grand narrative of peace.

The section ends with the chapter by Rob van der Laarse, who explores conflicts of the "ownness" of intangible cultural heritage through examples from the recent (political) rediscovery of folklore in contemporary Europe. The promotion of, and identification with, national and regional folklore have recently been hijacked by European populist parties and movements. In their discourses, real and imaged folklore phenomena have been transformed into political means to foster territorial cultural identities and their "authenticity". Using examples from the Netherlands, the chapter critically discusses the UNESCO Convention for the Safeguarding of Intangible Cultural Heritage (2003) 
and its role in stimulating contestation of heritage's ownership by enabling (political) actors to utilize the concept of intangible cultural heritage for cultural identity-building projects. Moreover, van der Laarse explores how emotionality is intertwined with intangible cultural heritage, and how this entanglement can easily cause emotionally charged conflicts and even exclusion over heritage. The question of "ownness" is explored through the example of folk songs and fairy tales that are recognized as particular to several different European countries.

In the relationship between bordering practices and mobility, the second section identifies the contested ground where dissonances between and across politics from "below" and from "above" emerge. The authors in this section scrutinize the reactions and responses to national and European institutions' "authorized heritage discourses" by exploring exhibitions and urban spaces. By emphasizing the individual, the body, and experience in memory and heritage politics, their analysis offers different perspectives on these aspects' roles and effects on memorialization and heritagization processes in today's Europe.

In the first chapter, Milica Trakilović examines Europe's internal borders as building blocks of European cultural heritage and identity. The chapter uses a phenomenological approach to explore the connections between spaces, bodies, and European identity and the figure of the migrant and the refugee in the creation of a European space. Using Schiphol airport in the Netherlands as a case study of the airport as a bordered cultural space and building on interviews with asylum seekers, the chapter explores how the borders of the Dutch cultural archive affect the experience of "unwelcome" others. As this symbolic archive is built on the country's colonial legacy, the chapter draws parallels to the larger European cultural archive to showcase how the European identity is protected by erecting "a myriad of invisible new borders that are ideological, radicalized, and politicized" (Ponzanesi and Blaagaard 2011, 3).

Sigrid Kaasik-Krogerus' chapter confronts the notion of mobility in Europe with stabilization and domestication processes. She explores the dissonance between forced or voluntary mobility and stability through exhibitions in the Great Guild Hall, a medieval guild building in Tallinn that functions as the venue for the Estonian History Museum, awarded with the European Heritage Label in 2014. The chapter indicates how two of these exhibitions seek to "Europeanize" heritage while simultaneously domesticating the "European" as well, that is, incorporating 
it within the national and local context and making it familiar on the national and local level. The European thus becomes part of a national and local narration as the exhibitions construct Europe as a multi-scalar process.

The volume's final section discusses present-day Europe's relationship with its colonial heritage and memory, and the postcolonial interpretations and critical cultural interventions that seek to respond to this legacy to recognize and dismantle the power hierarchies affecting present-day heritage and memory regimes and their identity-building processes. The section focuses on spatiality and geography and explores the colonial legacy from both macro-level national and European narratives and individual experiences, emotions, and actions. Similarly to Lähdesmäki, Mäkinen, and Kaasik-Krogerus, this section's first chapter, written by Johanna Turunen, focuses on European authorized heritage discourse. By analyzing EU policy documents related to the European Heritage Label, Turunen explores the relationship between "European values" and the construction of "Europeanness", re-evaluating and reconstructing these values' meanings in the broader frame of European history. Using postcolonial theory, the chapter seeks to show how "European values" (like the ones related to the EU as a 'peace project', see Mäkinen's chapter) take on ambivalent and dissonant meanings, especially when analyzed from the vantage point of the often silenced and hidden heritage of European imperialism. These reflections foreground how the emphasis on "European values" forges exclusionary narratives of Europeanness, an analysis that resonates with the argument developed in Kaasik-Krogerus' chapter.

Iris van Huis continues the analysis of Europe's colonial heritage by focusing on the Dutch colonial past and the contestation of its present-day meanings and uses. This chapter further elaborates on "politics", which van Huis deals with as interventions by change agents and activist critical groups, including impacts of these interventions, thus emphasizing politics as an active and activist act "from below". The chapter returns to the discussion of the contesting ethno-nationalist and postcolonial discourses that characterize the current public debates on heritage in many European countries. Like van der Laarse and Trakilović, van Huis also focuses on issues related to the Netherlands' colonial past. Scrutinizing Amsterdam's Tropenmuseum, she asks how it has portrayed the past and how activist individuals and groups now contest and seek to change the prevailing racist and discriminatory 
dimensions of the Dutch cultural archive- of which the Tropenmuseum functions as an example.

The section ends with a chapter by Gabriele Proglio, who discusses the idea of dissonant memories in the Mediterranean basin. He develops the notion of "emotional geography" in relation to Europe's official and canonized geography, and explores dissonant memories of recent refugee crises and immigration from Africa that not just migrants from Ethiopia, Eritrea, and Somalia in Italy have, but also the second-generation people who were born in Italy but are still culturally connected to the Horn of Africa. Proglio's analysis of the interview data shows how the memory of crossing the Mediterranean-also when this experience and memory is not direct but intersubjectively shared in the diasporic community - can elaborate new forms of cultural identities through emotions. Similarly to van Huis and Turunen's approaches, Proglio's conceptualization of the Black Mediterranean helps foreground forms of resistance to the coloniality of power that informs mainstream representations of contemporary Europe.

The volume ends with Luisa Passerini's Epilogue, which discusses the theoretical and conceptual implications of the volume in decentering heritage and memory. Looking at the terminological and conceptual history of terms such as "heritage" and "dissonance", Passerini's reflections point to possible directions for future research and debates in heritage and memory studies and beyond.

Acknowledgements This work received funding from the European Research Council under the European Union's Seventh Framework Programme (FP/2007-2013), ERC Grant Agreement number 29585 (BABE), as well as under the EU's Horizon 2020 Research and Innovation Programme under Grant Agreement number 636177 (EUROHERIT).

\section{REFERENCES}

Bhambra, G.K. 2014. Connected Sociologies. London: Bloomsbury Academic. Brockmeier, J. 2010. After the Archive: Remapping Memory. Culture and Psychology 16 (1): 5-35.

Davidson, J., M.M. Smith, and L. Bondi (eds.). 2012. Emotional Geographies. New York: Routledge.

Deacon, H. 2004. Intangible Heritage in Conservation Management Planning: The Case of Robben Island. International Journal of Heritage Studies 10 (3): 309-319. 
De Cesari, C., and A. Rigney. 2014. Introduction. In Transnational Memory: Circulation, Articulation, Scales, ed. C. De Cesari and A. Rigney, 1-15. Berlin: De Gruyter.

De Genova, N. 2016. The European Question: Migration, Race and Postcoloniality in Europe. Social Text 34 (3): 75-102.

De Genova, N. 2017. The Borders of "Europe": Autonomy of Migration, Tactics of Bordering. Durham: Duke University Press.

Delanty, G., and C. Rumford. 2005. Rethinking Europe. Social Theory and the Implications of Europeanization. London: Routledge.

Dicks, B. 2000. Heritage, Place and Community. Cardiff: University of Wales Press.

Donnan, H., M. Hurd, and C. Leutloff-Grandits. 2017. Migrating Borders and Moving Times. Temporality and the Crossing of Borders in Europe. Manchester: Manchester University Press.

Erll, A. 2011. Travelling Memory. Parallax 17 (4): 4-18.

Goldberg, D.T. 2006. Racial Europeanization. Ethnic and Racial Studies 29 (2): 331-364.

Innocenti, P. (ed.). 2014. Migrating Heritage: Experiences of Cultural Networks and Cultural Dialogue in Europe. Furhnam, Surrey: Ashgate.

Karlsson, K. 2010. The Uses of History and the Third Wave of Europeanization. In A European Memory? Contested Histories and Politics of Remembrance, ed. M. Pakier and B. Stråth, 38-55. New York and Oxford: Berghahn Books.

Kennedy, R., and M. Nugent. 2016. Scales of Memory: Reflections on an Emergent Concept. Australian Humanities Review 59 (April-May): 61-76.

Kisić, V. 2017. Governing Heritage Dissonance: Promises and Realities of Selected Cultural Policies. Amsterdam: European Cultural Foundation.

Lawler, S. 2002. Narrative in Social Research. In Qualitative Research in Action, ed. T. May, 242-258. London: Sage.

Lähdesmäki, T. 2014. The EU's Explicit and Implicit Heritage Politics. European Societies 16 (3): 401-421.

Lähdesmäki, T. 2017. Narrativity and Intertextuality in the Making of a Shared European Memory. Journal of Contemporary European Studies 25 (1): 57-72.

Macdonald, S. 2013. Memorylands: Heritage and Identity in Europe Today. London: Routledge.

Mezzadra, S., and B. Neilson. 2013. Borders as Method, or, the Multiplication of Labor. Durham: Duke University Press.

Oates-Indruchová, L., and W. Mueller. 2017. From the Iron Curtain to the Schengen Area: Memory Cultures of Bordering Communist and Postcommunist Europe. East European Politics and Societies and Cultures 31 (2): 227-233.

Pakier, M., and B. Stråth (eds.). 2010. A European Memory? Contested Histories and Politics of Remembrance. New York and Oxford: Berghahn Books. 
Passerini, L. 2007. Memory and Utopia: The Primacy of Inter-subjectivity. London: Routledge.

Passerini, L., D. Gabaccia, and F. Iacovetta. 2016. 'Bodies Across Borders. Oral and Visual Memory in Europe and Beyond' (BABE): A Conversation with Luisa Passerini, Donna Gabaccia, and Franca Iacovetta. Women's History Review 25 (3): 458-469.

Ponzanesi, S., and B.B. Blaagaard. 2011. In the Name of Europe. Social Identities 17 (1): 1-10.

Rotheberg, M., and D. Moses. 2014. A Dialogue on the Ethics and Politics of Memory. In The Transcultural Turn: Interrogating Memory Between and Beyond Borders, ed. L. Bond and J. Rapson, 29-38. Berlin and Boston: De Gruyter.

Said, E. 2000. Invention, Memory, and Place. Critical Inquiry 26 (2): 175-192.

Scott, J.W. 2011. The Fantasy of Feminist History. Durham and London: Duke University Press.

Smith, L. 2006. Uses of Heritage. London: Routledge.

Smith, L., and N. Akagawa (eds.). 2009. Intangible Heritage. London: Routledge.

Tunbridge, J.E., and G.J. Ashworth. 1996. Dissonant Heritage: The Management of the Past as a Resource in Conflict. Chichester: Wiley.

Van Houtum, H. 2013. Human Blacklisting: The Global Apartheid of the EU's External Border Regime. In Geographies of Privilege, ed. F. Winddance Twine and B. Gardener, 957-976. London: Routledge.

Waterton, E., and L. Smith. 2009. There Is No Such Thing as Heritage. In Taking Archaeology out of Heritage, ed. E. Waterton and L. Smith, 10-27. Cambridge: Cambridge Scholars Publishing.

Wekker, G. 2016. White Innocence: Paradoxes of Colonialism and Race. Durham, NC: Duke University Press.

Yuval-Davis, N. 2011. The Politics of Belonging: Intersectional Contestations. London: Sage. 
Open Access This chapter is licensed under the terms of the Creative Commons Attribution 4.0 International License (http://creativecommons.org/licenses/ by $/ 4.0 /$ ), which permits use, sharing, adaptation, distribution and reproduction in any medium or format, as long as you give appropriate credit to the original author(s) and the source, provide a link to the Creative Commons license and indicate if changes were made.

The images or other third party material in this chapter are included in the chapter's Creative Commons license, unless indicated otherwise in a credit line to the material. If material is not included in the chapter's Creative Commons license and your intended use is not permitted by statutory regulation or exceeds the permitted use, you will need to obtain permission directly from the copyright holder.

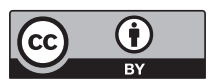

